\title{
LA ESTROFA SÁFICA \\ EN DOS POETAS CORDOBESES: RICARDO MOLINA Y PABLO GARCÍA BAENA
}

\author{
José EnRiQue Martínez FernÁNDEZ
}

Resumen: Tras una breve referencia al recorrido histórico de la estrofa sáfica, se realiza un análisis métrico y hermenéutico de las composiciones en la mencionada estrofa por parte de dos poetas cordobeses de la revista Cántico: Ricardo Molina y Pablo García Baena. Se ponen de manifiesto las variaciones rítmicas introducidas en la forma clásica. Las formas estróficas canónicas sobreviven en la poesía contemporánea, acomodándose rítmicamente al fluir del sentimiento poético.

Palabras clave: Estrofa sáfica, variaciones rítmicas, flexibilidad.

\begin{abstract}
After a brief reference to the historical background of the sapphic verse, the study of the metrical and hermeneutical analysis of the compositions of the hitherto mentioned verse has been limited to two poets from Córdoba, whose works are included in the journal Cántico: Ricardo Molina and Pablo García Baena. The rhythmic variations introduced in the classic form are developed. The canonical forms of that verse remain in the contemporaneous poetry since they are rhythmically adjusted to the flow the poetic feeling.
\end{abstract}

Key words: Sapphic verse, rhythmic variations, flexibility. 

$\mathrm{L}$

LAMAMOS estrofa sáfica a un conjunto iterable de cuatro versos sueltos, de los cuales los tres primeros son endecasílabos sáficos y el último, pentasílabo adónico; esta definición estricta se modula atendiendo a determinadas variaciones que la estrofa ha sufrido a lo largo del tiempo, bien por la aparición de formas asonantadas o aconsonantadas, bien por distintas matizaciones del ritmo acentual.

La estrofa sáfica fue empleada en la traducción de poesía clásica, intentando imitar su forma métrica, tanto en italiano como en español. De Italia la importó Antonio Agustín, utilizándola en una poesía que allí escribió y que dio a conocer Menéndez Pelayo. El camino histórico recorrido por la estrofa clásica puede seguirse en Baehr (1970: 364-369) y a lo largo de las páginas de la Métrica española de Navarro Tomás (1991). Lo recordaré en rápido resumen. Dicha combinación estrófica la usaron también el Brocense, en su traducción del "Rectius vives" de Horacio, y Jerónimo Bermúdez, éste con apreciables variaciones rítmicas ${ }^{1}$. Fue Esteban Manuel Villegas, sin embargo, quien fijó nítidamente el modelo de la estrofa sáfica en su conocida oda "Al céfiro": "Los quince endecasílabos de sus cinco estrofas presentan acentos en las sílabas cuarta y octava; el acento de la cuarta recae sobre palabra llana; diez de estos versos llevan también acento sobre la primera sílaba; los cinco adónicos son uniformemente pentasílabos dactílicos" (Navarro Tomás, 1991: 261). La oda ha gozado de celebridad por su acierto en la adaptación de los metros clásicos y por su perfección formal. Menos conocida es su oda sáfica "La paloma". También Baltasar del Alcázar usó la

\footnotetext{
1 "En lo que se refiere al ritmo todas estas pruebas tempranas tienen en común el libre uso de diferentes tipos de endecasílabos, tal como en Italia" (Baehr, 1970: 366).
} 
estrofa sáfica (“A Cupido"), que en el Neoclasicismo y el Romanticismo tuvo cultivo extraordinario como modo de imitación de los metros clásicos, con Jovellanos, Meléndez Valdés, Cadalso y otros, así como con Zorrilla o el Duque de Rivas, por citar sólo a los poetas de mayor relieve. En general siguieron el modelo de Villegas, pero introduciendo en él notables innovaciones, como asonancias o consonancias en los versos pares de cada estrofa, o asonancia en los versos pares de toda la composición, a manera de romance, entre otras alternativas. La estrofa sáfica contó con escasos ejemplos en la poesía modernista, destacando la atención que le prestó Unamuno en numerosos poemas, como pormenorizó Navarro Tomás (1991: 409-410), pero con tales desviaciones que, como escribió Baehr (1970: 369), "parece que el fin que se proponía era precisamente evitar el tipo clásico".

No conozco estudios sobre el uso de la estrofa sáfica en el postmodernismo y en la poesía contemporánea, ni tiene este trabajo tal finalidad, pues se restringe al examen métrico, con algunas derivaciones hermenéuticas, de las composiciones en estrofas sáficas de dos poetas cordobeses a los que el destino unió, en sus primeros afanes líricos, en torno a la aventura de la revista Cántico en sus dos épocas: 1947-1949, en que salieron ocho números, y 1954-1957, con once números en la calle. Se trata de Ricardo Molina (Puente Genil, 1917-Córdoba, 1968) y Pablo García Baena (Córdoba, 1923).

De la poesía del primero se ha destacado su vitalismo -a pesar de su tono elegíaco-, que brota de una palabra reflexiva y emotiva a la vez, la cual celebra "la fugaz belleza terrestre", como dice uno de sus versos. También la poesía de García Baena expresa un sentir elegíaco, pero en ella sobresalen poderosamente la sensualidad a flor de verso, los elementos culturalistas y el lenguaje suntuoso, cimentado en la profusión de adjetivos y en el uso de imágenes de cuño barroco y de gran riqueza visual, así como un exquisito sentido rítmico.

Poco después de las Elegías de Sandua (1948), acaso el poemario mayor de Molina, se publicaron Tres poemas, también en 1948, un libro minusvalorado por la crítica. Se trata de largas composiciones, la tercera de las cuales se titula "El poema de Pablo García Baena", que puede adscribirse al existencialismo 
religioso de posguerra, con un estilo sobreabundante en versos apasionados de largo trazado. El poema, dirigido a Dios, plantea inicialmente este argumento: el poeta (yo) busca signos que confirmen su fe; ningún signo es más profundo que la criatura humana, hecha a imagen y semejanza de Dios; y entre ellas ninguna mayor que el hombre inspirado, por lo que la segunda parte del poema "se detiene un momento en el ángelus suave / donde está con vos, solo, Pablo García Baena", en un silencio fértil o atento a los rumores ocultos de la naturaleza; la tercera parte expresa una visión exaltada del poeta, predestinado, profético, elevado por encima de los demás hombres, pues "por la escala estremecida de la belleza asciende hasta la visión de vuestra hermosura"; poeta es Pablo, ardiendo, como poeta que es, en sed divina, aunque él mismo la ignore, sin que nada pueda apartarlo "de su senda encendida flanqueada de arcángeles". No se olvidó Molina de "este hermano mío", como calificó a García Baena en la composición anterior, en su larga serie de poemas acogidos al título de Homenaje ${ }^{2}$. Una de las piezas lleva por título "Invitación al mundo exterior. Homenaje a Pablo García Baena"; en ella Molina insta al amigo a despertar de sus sueños, a salir de sí mismo y entregarse al mundo y su hermosura: "Sal de tu desmayo, / despierta, abre los ojos, alma, y mira".

Por su parte, García Baena homenajeó al amigo, ya muerto, en su libro Antes que el tiempo acabe (1978), dentro de la sección titulada "Los poetas", que acoge homenajes a poetas que cifran el gusto personal del autor, unido en algunos casos a la amistad (Ibn Hazm, San Juan de la Cruz, Góngora, Juan Ramón Jiménez, Jorge Guillén, Gerardo Diego, Emilio Prados, Cernuda y Molina). El homenaje a Ricardo Molina se titula "Sandua", en alusión a las Elegías de Sandua, y comienza como la "Elegía VII", desde mi punto de vista la más emocionante del poemario: "En Sandua aúlla el viento..."; como se sabe, Sandua, nombre de una mansión arruinada y de su entorno, constituyó el escenario

\footnotetext{
${ }^{2}$ Homenaje quedó inédito tras la muerte del poeta. Se recogió en parte en Antología (1945-1967), de Ricardo Molina, que corrió a cargo de Mariano Roldán y publicó la editorial barcelonesa Plaza \& Janés; apareció entero en Obra poética completa, vol. 2 (Molina, 1982), fijada y ordenada por Pablo García Baena, María Victoria Atencia, Rafael León y Bernabé Fernández-Canivell.
} 
amoroso de las Elegías. El poema de García Baena remite a la "Elegía VII" incluso métricamente, al adoptar una de las estrofas de aquella: el quinteto en alejandrinos sueltos; pero "Sandua" es, ante todo, una evocación emocionada del amigo muerto, de los lugares que amó y cantó, de la Sandua en ruinas...

En siete composiciones emplea Molina la estrofa sáfica ${ }^{3}$; García Baena sólo en dos. Acaso convenga añadir que la obra poética del primero es bastante más extensa que la del segundo.

Las composiciones sáficas de Ricardo Molina son las siguientes: "Variaciones en metro sáfico sobre una canción vulgar" (Corimbo, 1949), "Vino antiguo" y "Cuán silencioso reino..." (Elegía de Medina Azahara, 1957), "Rondel. Homenaje a Francis Jammes", "Adoradores del sol. Homenaje a André Gide", "Camino viejo de la campiña de Córdoba. Homenaje a Gerardo Diego" y "Oda a Antonio Mairena (Homenaje).

Pablo García Baena escribe en estrofas sáficas el poema "Ronda"4 por entero (diez estrofas) y parte del poema "Delfos" (seis estrofas iniciales), éste dentro del poemario Antes que el tiempo acabe (1978).

El análisis métrico se centrará primeramente en los poemas citados de Ricardo Molina.

A los acentos en las sílabas cuarta y octava, además de la décima, propios del verso sáfico, metricistas como Bello, Juan Gualberto González, Benot y otros (Caparrós, 1975: 482-483) habían añadido algunos requisitos que Domínguez Caparrós (1999: 143) resume así:

Debe llevar un acento en la primera sílaba; admite muy bien una pausa de sentido entre la quinta y sexta sílaba, y la palabra que lleva el acento en la cuarta sílaba debe ser, por lo tanto, llana. Bello añade: que sean átonas las sílabas segunda, tercera, sexta -recordemos que Navarro Tomás y Emiliano Díez

\footnotetext{
${ }^{3}$ No aludiré a composiciones cercanas en su estructura a la estrofa sáfica, como las compuestas en la llamada "estrofa de la Torre", sobre la base de tres endecasílabos y un heptasílabo sin rima.

4 "Ronda" aparece entre los "Poemas no incluidos en libro" de la Poesía completa del autor (García Baena, 1998) y entre los "Poemas no recogidos en libros y uno inédito" de Recogimiento (Poesía, 1940-2000).
} 
Echarri admiten el acento en sexta ${ }^{5}$ y novena; que no haya sinalefa en la cesura, es decir, que se evite el encuentro de vocales en este lugar.

El modelo era, naturalmente, la oda de Villegas "Al céfiro". Tales eran las "normas estilísticas" -así las llama Domínguez Caparrós- que se sumaban a las normas métricas; pero como indica Baehr (1970: 140), "los poetas, antes y después de Bello, se han guiado en el uso del sáfico más por sus propias intuiciones rítmicas que por reglas teóricas"; más aún: el endecasílabo de la llamada estrofa sáfica ha combinado, con gran frecuencia, todos los tipos del mismo, singularmente los italianos con acento fijo en sexta sílaba, prefiriendo la variedad rítmica -tal es el caso de Ricardo Molina, como veremos- a la uniformidad estricta que observaron, por ejemplo, poetas neoclásicos como Cadalso, Jovellanos, Iglesias de la Casa o Noroña ${ }^{6}$. Por lo que se refiere al pentasílabo adónico (o dactílico), con acento en primera y cuarta sílabas, con el que Villegas quiso reproducir el adónico clásico (dactílico más espondeo), su uso es más regular dentro de la estrofa sáfica.

Si analizamos métricamente los poemas de Ricardo Molina elaborados sobre la forma de la estrofa sáfica -todos ellos relativamente breves, compuestos de cuatro, cinco o seis estrofas; sólo uno de ellos se resuelve en nueve estrofas- podemos extraer las siguientes conclusiones:

a) Todas las estrofas de tipo sáfico discurren en versos sueltos conforme al patrón clásico establecido por Villegas.

b) El endecasílabo sáfico (llamo así únicamente al acentuado en cuarta y octava sílabas) no es más que una posibilidad -bastante escasa, por lo demás- entre los diferentes tipos de endecasílabo.

\footnotetext{
${ }^{5}$ Uno y otro tratadistas consideran endecasílabos sáficos tanto a los que llevan acentos en cuarta y octava como a los que lo llevan en cuarta y sexta.

${ }^{6}$ El padre Iglesias de la Casa, por ejemplo, es autor de una "Oda en sáficos-adónicos" cuya primera estrofa dice así:

¿De qué me sirve, Primavera hermosa, que nueva vida a tus pensiles vuelvas, y aquestas selvas llenes de frondosos álamos verdes? (Carnero, 1970: 74)
} 
c) El pentasílabo que cierra cada estrofa suele ser adónico, con acento en primera y cuarta sílabas, si bien admite otras posibilidades (acentos en segunda y cuarta sílabas, por ejemplo), entre las que la de mayor frecuencia es un único acento en cuarta sílaba (pentasílabos como "inalterable", "de la montaña", "e interminable", etc.).

d) Del esquema trazado (estrofa compuesta de tres endecasílabos variados rítmicamente, más un pentasílabo de mayor regularidad, es decir, que tiende a ser adónico) únicamente se separa Molina en dos casos: en uno de ellos, la primera estrofa del poema "Variaciones en metro sáfico..." termina en heptasílabo: "en Egipto cantara"; en el otro, la primera estrofa del poema "Vino antiguo" comienza con un alejandrino: "Loca sabiduría del corazón, ensueño".

A mi parecer, la variedad rítmica endecasilábica se explica en razón de las libertades usuales en la poesía moderna, que cuando se enmarca en las formas clásicas, frecuentemente acaba violentando algunas de las normas que las rigen. Por otro lado, hay un acercamiento entre la estrofa sáfica clásica y la estrofa de la Torre, muy próximas en su estructura, ya que la segunda, derivó probablemente de la primera. Ésta se diferenciaba, además de por el heptasílabo de cierre en cada estrofa, por la mezcla de los diferentes ritmos endecasilábicos. La estrofa sáfica, primera en el tiempo, tiende, pues, a adoptar las libertades rítmicas de la estrofa de la Torre?

Nos acercaremos ahora brevemente a alguno de los poemas de Ricardo Molina compuestos en estrofas sáficas. El primero de este tipo afirma explícitamente en el título su adscripción métrica: "Variaciones en metro sáfico sobre una canción vulgar" (Corimbo). A ésta, la canción vulgar, se alude en los dos primeros versos: "Casi ahogada la voz, lánguidamente, / decía que una vez sólo se vive". La canción provoca la meditación desesperanzada sobre la vida y el tiempo, en respuesta a preguntas sobre aquella (“¿Qué hice hasta ahora? ¿Dónde está mi vida?”) y sobre

\footnotetext{
${ }^{7}$ Ricardo Molina compuso escasos poemas en estrofas de la Torre, que no forman parte de nuestro análisis métrico; por ejemplo, "Toco la piedra", de Elegía de Medina Azahara.
} 
éste (“¿Qué hizo el tiempo de mí? ¿Qué hice del tiempo?”). El metro sáfico al que alude el título se refiere a la forma externa del poema: seis estrofas que combinan tres endecasílabos más un pentasílabo, con la excepción ya indicada de la primera, que concluye con un heptasílabo. En realidad, sólo cinco de los dieciocho endecasílabos pueden adscribirse al esquema del sáfico, con acentos en cuarta y octava sílabas, además de otros acentos interiores ajenos a la normativa establecida por Bello y otros metricistas; algunos de esos cinco endecasílabos, por ejemplo, llevan acento también en sexta sílaba, que para Bello debía ser necesariamente átona; es el caso de endecasílabos como:

¿Qué hice hasta ahora? ¿Dónde está mi vida?

Aún en el caso de que, con Navarro Tomás, llamáramos sáfico al endecasílabo con "tiempo marcado en la sílaba cuarta" y "asiento secundario" en sexta, sólo añadiríamos tres endecasílabos más a los cinco sáficos anteriores; son versos como éste:

cuanto me hiere, besa o enamora

Cabe concluir que estos endecasílabos son, por lo tanto, aleatorios en un poema que combina libremente todo tipo de endecasílabos: además de los indicados, las distintas clases del "endecasílabo a maiore", es decir, acentuado en sexta, con otros acentos interiores variables.

En cuanto a los pentasílabos, de los cinco, tres son adónicos; los otros, yámbicos, con acentos en sílabas segunda y cuarta. Todo nos lleva a hablar, por lo tanto, de variabilidad rítmica, como podemos comprobar en la estrofa que ofrecemos como muestra, la tercera:

En palabras hermosas se me cambia cuanto me hiere, besa o enamora. Todo se me convierte a pesar mío en dulce canto.

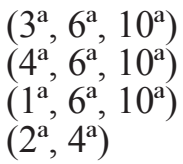

$(2,4)$ 
El análisis de las demás composiciones de este tipo nos llevaría a unas conclusiones parecidas, que se resumen diciendo que no parece que aliente en Ricardo Molina la intención de construir versos sáficos, sino que se guía rítmicamente por la tradición más asentada en nuestra poesía, que es el uso polirrítmico del endecasílabo. He aquí un nuevo ejemplo demostrativo, elegido al azar, tanto el poema ("Rondel. Homenaje a Francis Jammes") como la estrofa:

\begin{abstract}
El pétalo inocente en sus secretos canales atesora más veneno que la ortiga punzante... Desconfía de la belleza.
\end{abstract}

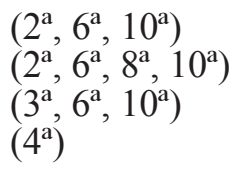

La excepción la constituye el poema titulado "Camino viejo de la campiña de Córdoba. Homenaje a Gerardo Diego". Son nueve estrofas sáficas y en ellas todos los endecasílabos (salvo tres de ellos, con acentos en $2^{\mathrm{a}}$ y $6^{\mathrm{a}}$, en $3^{\mathrm{a}}$ y $6^{\mathrm{a}}$ y en $4^{\mathrm{a}}$ y $6^{\mathrm{a}}$ respectivamente), portan acentos en cuarta y octava sílabas (algunos de ellos también en sexta) y varios de ellos (nueve, al menos) también en primera, como pedían los tratadistas más conspicuos. Tal regularidad no se debe, creo yo, a que se trate de un homenaje al maestro Diego, que en su empleo de la estrofa sáfica en el poema "Magritas" ("El Cordobés" dilucidado, 1966) se decidió por el endecasílabo de ritmo dactílico (acentos en $1^{\mathrm{a}}, 4^{\mathrm{a}}$ y $\left.7^{\mathrm{a}}\right)^{8}$. En cualquier caso, el poema de Molina se desarrolla en estrofas sáficas, con ritmo endecasílabo uniforme casi en su totalidad; también los pentasílabos son de ritmo dactílico, es decir, adónicos en seis de las nueve estrofas. Trascribo las dos primeras, con afán de ejemplificar el breve análisis efectuado:

Camino polvoriento y sinuoso de los lagares bajo el sol de julio, río que exhausto desemboca en verde mar de viñedos, $\left(2^{\mathrm{a}}, 6^{\mathrm{a}}\right)$

$\left(4^{\mathrm{a}}, 6^{\mathrm{a}}, 8^{\mathrm{a}}\right)$

$\left(1^{\mathrm{a}}, 4^{\mathrm{a}}, 8^{\mathrm{a}}\right)$

$\left(1^{\mathrm{a}}, 4^{\mathrm{a}}\right)$

${ }^{8}$ Dice así la segunda estrofa de "Magritas":

Andan sus pasos prudentes y sabios,

Andan de frente, cuartean apenas,

Suben y bajan sus brazos. Atenas

Nace de nuevo. 
aunque el primero que del cuerpo, un día, $\left(4^{\mathrm{a}}, 8^{\mathrm{a}}\right)$

te abrió en el seno florecido yazga

$\left(2^{\mathrm{a}}, 4^{\mathrm{a}}, 8^{\mathrm{a}}\right)$

olvidado en la noche mineral

infranqueable.

Como decíamos, sólo dos composiciones de García Baena se desarrollan en estrofas sáficas, "Ronda" y "Delfos". El motivo es muy próximo: dos ciudades; pero el sentimiento poético es muy distinto. El poema primero -encuadrado en la poesía completa de García Baena (1988) ${ }^{9}$ entre los "Poemas no incluidos en libro", sin fecha de publicación inicial- es un canto a la ciudad malagueña de Ronda ("a ti te canto") evocando su belleza en equilibrio ante el abismo por medio de una profusión de suntuosas imágenes ("ala entreabierta", "jinete del suicidio despeñándose", "surtidor que detiene su obelisco", "Ángel en vuelo inmóvil permanente", etc.) que llenan las cuatro primeras estrofas; en las seis últimas, Ronda se humaniza con canciones melancólicas en la noche, que expresan intensas pasiones; el pentasílabo final ("piedra y suspiro") resume y une los dos motivos del poema. En cambio, el poema "Delfos"-que con "Venecia" y "Córdoba" compone la sección titulada "Las ciudades", de Antes que el tiempo acabe-canta las ruinas que "publica el amarillo jaramago", podríamos decir con Rodrigo Caro, pues tras evocar plásticamente los "almenados bucles" de la ciudad, canta la ruina de su frente altiva, con evocaciones históricas de humillaciones y asolamientos, para terminar con las "gualdas flautas" del jaramago, que es quien, a falta de los cantos y ritmos antiguos, lanza ahora "hímnicos cantos". Pero el motivo de las ruinas, que abarca las seis estrofas sáficas del poema, se convierten en el resto del poema (treinta y cinco versos de distintas medidas) en correlato del espíritu desesperanzado del poeta ("¿Qué esperas del oráculo, Pablo García Baena?’).

Desde el punto de vista métrico, uno y otro poema (de "Delfos" tendré en cuenta únicamente las seis estrofas sáficas) comienzan con endecasílabos sáficos:

9 Posteriormente, en 2006, García Baena publicó el poemario titulado Los campos Elíseos (Valencia: Pre-Textos), en el cual no hay estrofas sáficas. 
Blanca en la dicha de tu cal insomne

Ronda del aire, de la luz y el lirio

Alza la frente de almenados bucles $\left(1^{\mathrm{a}}, 4^{\mathrm{a}}, 8^{\mathrm{a}}\right)$

$\left(1^{\mathrm{a}}, 4^{\mathrm{a}}, 8^{\mathrm{a}}\right)$ ("Ronda")

$\left(1^{\mathrm{a}}, 4^{\mathrm{a}}, 8^{\mathrm{a}}\right)$ ("Delfos")

Pero ambos poemas avanzan enseguida hacia la polirritmia, si bien se acusa una fuerte tendencia hacia el ritmo yámbico, es decir, a colocar las tónicas en las sílabas pares, haciendo gala del gran sentido rítmico que la crítica ha alabado en el poeta; en efecto, en "Ronda", por ejemplo, quince de los treinta endecasílabos llevan acento únicamente en sílabas pares. Lo comprobamos en una estrofa de cada poema:

El agua se desploma, ¿o es el llanto? y un vuelo de palomas desde el Tajo sostiene en gallardía de espirales piedra y suspiro

Crecieron tus laureles para el cónsul el dux, el victorioso, los tiranos; te asolaron sacrílegas pezuñas del bestiario.

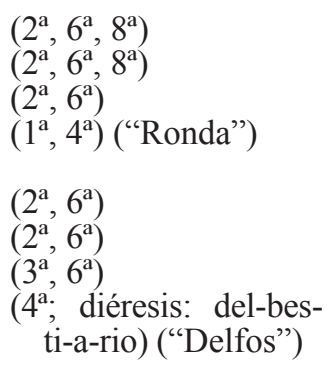
ti-a-rio) ("Delfos")

Tanto en "Ronda" como en "Delfos" hallamos endecasílabos sáficos (con acentos principales en $4^{\mathrm{a}}$ y $8^{\mathrm{a}} \mathrm{y}$, haciendo caso a Navarro Tomás, en $4^{\mathrm{a}}$ y $6^{\mathrm{a}}$ ), pero la gran mayoría de los endecasílabos los son "a maiore", con acento en sexta, encontrando todas las posibilidades que dicho metro ofrece para la posición del primer acento rítmico: en $1^{\text {a }}$ ("Surge la bailarina y sus tacones"), $2^{\mathrm{a}}$ ("los bríos andaluces en corceles") o $3^{\mathrm{a}}$ ("Por las calles en cuesta, por los arcos"). Me gustaría subrayar, asimismo, una cierta tendencia al paralelismo rítmico dentro de cada estrofa, como observamos en las que hemos trascrito antes o en otra que nos sirve ahora de ejemplificación, en la cual todos los endecasílabos son "melódicos" (para Navarro Tomás los que acentúan en tercera y sexta sílabas):

Por las calles en cuesta, por los arcos, por la libre baranda el heliotropo 
de la voz va enredando su caliente melancolía

("Ronda")

Todos los pentasílabos de "Ronda" y "Delfos" tienden al ritmo yámbico. En el primer poema mencionado sólo tres pentasílabos son adónicos: "ala entreabierta", "tiembla la estrella", "piedra y suspiro"; los demás llevan acento en $4^{\text {a }}$ (dos pentasílabos) o en $2^{\mathrm{a}}$ y $4^{\mathrm{a}}$ (cinco pentasílabos); en "Delfos" sólo uno es adónico: "hímnicos cantos"; el resto, yámbicos, con acento en $4^{\text {a }}$ (dos) o en $2^{\mathrm{a}}$ y $4^{\mathrm{a}}$ (tres).

Esta tendencia general a apoyar el ritmo en las sílabas pares da al conjunto un ritmo muy marcado, casi pétreo en su solidez. Por eso, justamente, cuando hay alguna desviación del patrón rítmico adoptado, el efecto estilístico es más percepcible. Así sucede en dos casos explícitos, uno en cada poema. Dice así la quinta estrofa de "Ronda":

Silencio, que hay guitarras junto al río en corazón sonoro de la noche y el jazmín tiende sus besos de fiebre si canta Ronda.

Los dos primeros versos son de ritmo yámbico, pero su sonoridad parece acrecentarse en el segundo verso, no sólo por la significación semántica del adjetivo "sonoro", sino porque el acento rítmico en $4^{\mathrm{a}}, 6^{\mathrm{a}}$ y $10^{\mathrm{a}}$ sílabas recae sobre la vocal grave $o$ (obsérvense, además, la seis recurrencias de la vocal $o$ ):

$$
\text { e-o-a-ó-o-ó-o-e-a-ó-e }
$$

Esta sonoridad se diluye, sin embargo, en el verso siguiente, no sólo porque las vocales rítmicas son otras (ie-a-í-ié-e-u-é-oe-ié-e), sino porque existe una apreciable variación rítmica, pues las sílabas tónicas son ahora $3^{\mathrm{a}}, 4^{\mathrm{a}}$ y $7^{\mathrm{a}}$, además de la $10^{\mathrm{a}}$.

En "Delfos" los dos primeros versos ofrecen un contraste significativo: 

Alza la frente de almenados bucles
$\left(1^{\mathrm{a}}, 4^{\mathrm{a}}, 8^{\mathrm{a}}, 10^{\mathrm{a}}\right)$ entre montañas, roto perfil póstumo
$\left(4^{\mathrm{a}}, 6^{\mathrm{a}}, 9^{\mathrm{a}}, 10^{\mathrm{a}}\right)$

El acento antiestrófico en novena (según la conocida denominación de Balbín), generalmente denostado por la teoría métrica, tiene en el segundo verso innegables efectos expresivos ${ }^{10}$ : la violenta ruptura del ritmo yámbico, al introducir un acento antiestrófico, potencia el significado del sintagma "roto perfil póstumo"; dicho metafóricamente, la sensación de quiebra rítmica concuerda con el quebrado perfil geológico en que se asienta la ciudad de "Delfos".

De lo dicho hasta aquí se desprende, a mi parecer, una conclusión que, probablemente, cabe generalizar: parece que algunas formas estróficas clásicas sólo pueden sobrevivir en la poesía contemporánea sobre una cierta flexibilidad acomodada al matizado fluir del sentimiento poético ${ }^{11}$.

10 "Esta clase de acentuación produce un efecto especialmente áspero y cacofónico, al oscurecer la percepción del último acento del verso. Esto no obsta para que, en alguna ocasión y conscientemente, el poeta pueda utilizar el efecto con intención estilística determinada dentro de un contexto" (Domínguez Caparrós, 1999: 14).

${ }^{11}$ Aunque no he indagado sobre el asunto, sospecho por mis lecturas que la estrofa sáfica es de escasísimo cultivo en la actualidad y que, cuando aparece, lo hace dentro de esa flexibilidad que he manifestado; así lo observo, por ejemplo, en "Canción" (Siesta en el mirador, 1979), "Aire vuestro" (Columbario, 1999) o "Partal, entretiempo" (Los pasos evocados, 2004), de Antonio Carvajal, un poeta que es, además, excelente conocedor, en la teoría y en la práctica, de la métrica tradicional. 


\section{Referencias bibliográficas}

BAEHR, RUDOLF (1970): Manual de versificación española. Madrid: Gredos (traducción y adaptación de R. Wagner y F. López Estrada).

CARNERO, GUILLERMO (1970): Antología de la poesía prerromántica española. Barcelona: Barral Editores.

DOMÍNGUEZ CAPARRÓS, JOSÉ (1975): Contribución a la historia de las teorías métricas en los siglos XVIII y XIX. Madrid: CSIC.

- (1999): Diccionario de métrica española. Madrid: Alianza Editorial.

GARCÍA BAENA, PABLO (1998): Poesía completa (1940-1997). Madrid: Visor.

- (2000): Recogimiento (Poesía, 1940-2000). Málaga: Ayuntamiento de Málaga (Col. "Ciudad del Paraíso")

MOLINA, RICARDO (1982): Obra poética completa, 2 vols. Córdoba: Diputación Provincial.

NAVARRO TOMÁS, TOMÁS: Métrica española. Barcelona: Labor (1 $1^{\mathrm{a}}$ ed., 1956). 